\title{
Cardiovascular magnetic resonance in pulmonary hypertension
}

\author{
William M Bradlow ${ }^{1,2}$, J Simon R Gibbs ${ }^{2}$ and Raad H Mohiaddin ${ }^{1 *}$
}

\begin{abstract}
Pulmonary hypertension represents a group of conditions characterized by higher than normal pulmonary artery pressures. Despite improved treatments, outcomes in many instances remain poor. In recent years, there has been growing interest in the use of Cardiovascular Magnetic Resonance (CMR) in patients with pulmonary hypertension. This technique offers certain advantages over other imaging modalities since it is well suited to the assessment of the right ventricle and the proximal pulmonary arteries. Reflecting the relatively sparse evidence supporting its use, CMR is not routinely recommended for patients with pulmonary hypertension. However, it is particularly useful in patient with pulmonary arterial hypertension associated with congenital heart disease. Furthermore, it has proven informative in a number of ways; illustrating how right ventricular remodeling is favorably reversed by drug therapies and providing explicit confirmation of the importance of the right ventricle to clinical outcome. This review will discuss these aspects and practical considerations before speculating on future applications.
\end{abstract}

Keywords: Right ventricle, pulmonary hypertension, pulmonary arterial hypertension

\section{Background}

Pulmonary hypertension $(\mathrm{PH})$ is the term given when mean pulmonary artery pressure (mPAP) is greater or equal to $25 \mathrm{mmHg}$ [1]. It also describes a collection of clinical conditions in which pulmonary artery pressures are elevated.

At the most recent World Health Organisation conference (Dana Point, California) in 2008, PH was classified into five distinct disease groups (Table 1). Group 1 features patients with pulmonary arterial hypertension (PAH) and represents the most widely investigated subset of PH. It is thought to occur in 15-50 persons per million. Although newer treatments have led to improved survival, the disease continues to be associated with a poor prognosis [2].

For each patient, a methodical approach is necessary to describe the cause(s) of $\mathrm{PH}$. Alongside right heart catheterisation, multimodality imaging plays a key part in this [3]. Echocardiography is the best screening test for $\mathrm{PH}$ whilst radioisotope ventilation-perfusion scanning remains the principal modality for the diagnosis of

\footnotetext{
* Correspondence: r.mohiaddin@imperial.ac.uk

${ }^{1}$ Cardiovascular Magnetic Resonance Unit, Royal Brompton Hospital, London, UK

Full list of author information is available at the end of the article
}

chronic thromboembolic pulmonary hypertension (CTEPH, Group 4). In patients with CTEPH being considered for pulmonary endarterectomy, computed tomography $(\mathrm{CT})$ helps determine operative suitability. High resolution $\mathrm{CT}$ is used to characterize lung disease.

It is twenty five years since the use of cardiovascular magnetic resonance (CMR) was first reported in PH [4]. Due to its spatial resolution and freedom from acoustic windows, it has emerged as the gold standard for assessment of right ventricular (RV) structure and function $[5,6]$. This is particularly important in $\mathrm{PH}$ where the RV has long been thought to be important to survival [7]. Despite this, current guidelines rank other modalities more highly [1]. Though not surprising given CMR's limited availability and evidence base, experience with this technique is accumulating rapidly. It therefore seems unlikely that its position in future guidelines will remain unchanged.

The CMR examination is focused on the right heart and pulmonary arteries which undergo characteristic changes in response to elevated pulmonary pressures (Table 2). It is thought that RV hypertrophy initially predominates to compensate for pressure overload [1] before RV dysfunction and dilatation occur. The development of tricuspid regurgitation exacerbates volume 
Table 1 Classification of PH and Pointers to Each Subset

\begin{tabular}{|c|c|c|c|}
\hline \multicolumn{2}{|c|}{$\begin{array}{c}\text { Dana Point } \\
\text { Clinical Classification }\end{array}$} & \multirow[t]{2}{*}{ Flags } & \multirow[t]{2}{*}{ Suggested Sequences } \\
\hline Group & Name & & \\
\hline 1. & $\mathrm{PAH}$ & Shunts, aberrant pulmonary veins & $\begin{array}{l}\text { Dedicated views, flow } \\
\text { mapping and MRA }\end{array}$ \\
\hline 2. & Left heart disease & $\begin{array}{l}\text { LV impairment, hypertrophy or wall motion abnormalities, dilated left atrium, } \\
\text { valvular disease } \\
\text { Pulmonary vein stenosis }\end{array}$ & $\begin{array}{l}\text { LGE and valve lesion } \\
\text { quantification } \\
\text { Cine SSFP, flow and MRA }\end{array}$ \\
\hline 3. & $\begin{array}{l}\text { Lung diseases and/or } \\
\text { hypoxia }\end{array}$ & $\begin{array}{c}\text { Emphysematous or fibrosed lung fields. However compared to high-resolution } \\
\text { computed tomography, CMR images lungs poorly }\end{array}$ & \\
\hline 4. & CTEPH & Filling defects in the pulmonary arteries & MRA \\
\hline 5. & $\begin{array}{l}\text { Unclear and/or } \\
\text { multifactorial mechanisms }\end{array}$ & $\begin{array}{l}\text { Lymphadenopathy } \\
\text { Absent spleen }\end{array}$ & LGE \\
\hline
\end{tabular}

PAH; Pulmonary arterial hypertension, CTEPH; chronic thromboembolic pulmonary hypertension, MRA; magnetic resonance angiography, LGE; late gadolinium enhancement SSFP: steady state free procession.

overload. RV failure causes right atrial (RA) pressure [7] and size [8] to increase; both of which are related to outcome. Falling RV stroke volume and abnormal interventricular septal motion attenuate left ventricular (LV) filling and stroke volume. The proximal PAs become dilated. Histologically evident structural changes include media thickening and accumulation of mucopolysaccharide ground substance [9].

\section{Practical Considerations for CMR in PH} Indications, Protocol and Interpretation of Findings

Patients may be referred with an established diagnosis of $\mathrm{PH}$, with a diagnosis that requires clarification or with $\mathrm{PH}$ of unknown aetiology. Conversely, features of $\mathrm{PH}$ may be unexpectedly encountered in patients referred with left heart disease (where they should be reported due to its prognostic importance) or in patients with dilated RVs previously thought to have arrhythmogenic right ventricular dysplasia.

A minimum data set should allow RV size and function to be assessed by quantifying biventricular volumes, ejection fraction (EF) and mass. RV and LV stroke volume can be derived by flow mapping of the main reporting cardiac output and index, flow mapping of the aorta should be used [10] since it is smaller, has more coherent flow patterns and less translational movement than the main pulmonary artery. In instances where thromboembolic disease has not previously been excluded, an MR angiogram (MRA) of the pulmonary arteries should be undertaken. The examination is completed with imaging of late gadolinium enhancement (LGE). A suggested protocol is shown in Table 3.

It is not possible to consistently identify a cause by CMR alone. However, in selected cases a specific underlying disease may be suggested by the presence of one or more features (Table 1). It is important to integrate these findings with the examination, being prepared to deviate from this protocol to allow a more detailed assessment at the same sitting.

In patients with features suggestive of shunt, dedicated anatomical imaging, cines, flow mapping and angiography should be undertaken. CMR is particularly helpful in the diagnosis of a sinus venosus defect and partial anomalous venous drainage [11] (Figure 1). If evidence of myocardial infarction or significant valvular heart disease exists, left heart causes (Group 2) become more likely.

Table 2 Right Heart Changes in Pulmonary Hypertension

\begin{tabular}{l}
\hline RV hypertrophy involving the papillary muscles, trabeculations and interventricular septum [72]. Asymmetric septal hypertrophy may be present \\
[73-75] \\
\hline Progressive RV dilatation until it becomes the dominant, apex-forming ventricle \\
\hline Abnormal interventricular septal motion \\
\hline Tricuspid regurgitation as a consequence of RV dilatation and stretching of the valve annulus \\
\hline Interatrial septum becomes convex leftwards reflecting elevated RA pressures \\
\hline Dilated RA \\
\hline Plethoric vena cavae \\
\hline Pericardial effusion
\end{tabular}

pulmonary artery and aorta respectively. When Diastolic dysfunction should be considered when LV 
Table 3 Suggested Imaging Protocol in PH

\begin{tabular}{|c|c|c|c|}
\hline \multirow[t]{2}{*}{ Sequence } & \multirow[t]{2}{*}{ Objective } & \multicolumn{2}{|r|}{ Slice } \\
\hline & & Prescription & Parameters \\
\hline Localisers & Identify the position of the heart & $\begin{array}{l}\text { Sagittal, coronal and axial } \\
\text { planes }\end{array}$ & \\
\hline Cines & $\begin{array}{l}\text { Define axes of both ventricles and } \\
\text { the great arteries }\end{array}$ & $\begin{array}{l}\text { HLA, VLA, SAX stack, LVOT, } \\
\text { LVOT cross cut, RV VLA, MPA, } \\
\text { MPA cross cut }\end{array}$ & $\begin{array}{c}\text { Retrospectively gated, steady state free procession, slice } \\
\text { thickness } 7 \mathrm{~mm} \text {, interslice gap } 3 \mathrm{~mm} \text {, FOV read } 340 \mathrm{~mm} \text {, } \\
\text { FOV phase } 75 \mathrm{~mm}\end{array}$ \\
\hline $\begin{array}{l}\text { Flow } \\
\text { Measurements }\end{array}$ & $\begin{array}{l}\text { To determine stroke volume through } \\
\text { main pulmonary artery and aorta }\end{array}$ & MPA/Ao & $\begin{array}{c}\text { Retrospectively gated,2D segmented Spoiled Gradient Echo } \\
\text { sequence. Slice thickness } 10 \mathrm{~mm} \text {, FOV read } 350 \mathrm{~mm} \text {, FOV } \\
\text { phase } 100 \mathrm{~mm}\end{array}$ \\
\hline $\begin{array}{l}\text { Magnetic } \\
\text { Resonance } \\
\text { Angiography }\end{array}$ & To assess the pulmonary arterial tree & $\begin{array}{l}\text { Ensure coverage of the lung } \\
\text { vasculature }\end{array}$ & $\begin{array}{l}\text { Non-ECG gated 3D Spoiled Gradient Echo sequence, slice } \\
\text { thickness } 1.30 \mathrm{~mm} \text {, FOV read } 400 \mathrm{~mm} \text {, FOV phase } 100 \mathrm{~mm}\end{array}$ \\
\hline $\begin{array}{l}\text { Late } \\
\text { Gadolinium } \\
\text { Enhancement }\end{array}$ & $\begin{array}{l}\text { To exclude areas of infarction and } \\
\text { determine the degree of insertion } \\
\text { region enhancement }\end{array}$ & $\begin{array}{l}\text { Short axis stack and long axis } \\
\text { acquisitions }\end{array}$ & $\begin{array}{l}\text { 2D segmented Spoiled Gradient Echo sequence with non- } \\
\text { selective inversion pulse sequence. Slice thickness } 8 \text { mm, } \\
\text { FOV read } 340 \text { mm, FOV phase } 75 \text { mm. LGE TI } 260 \text { mm } \\
\text { initially then alter accordingly }\end{array}$ \\
\hline
\end{tabular}

HLA; horizontal long axis, VLA; vertical long axis, SAX; short axis, LVOT; left ventricular outflow tract, RV; right ventricular, MPA; main pulmonary artery, Ao; aorta, FOV; field of view, LGE; Late Gadolinium Enhancement, TI, inversion time.

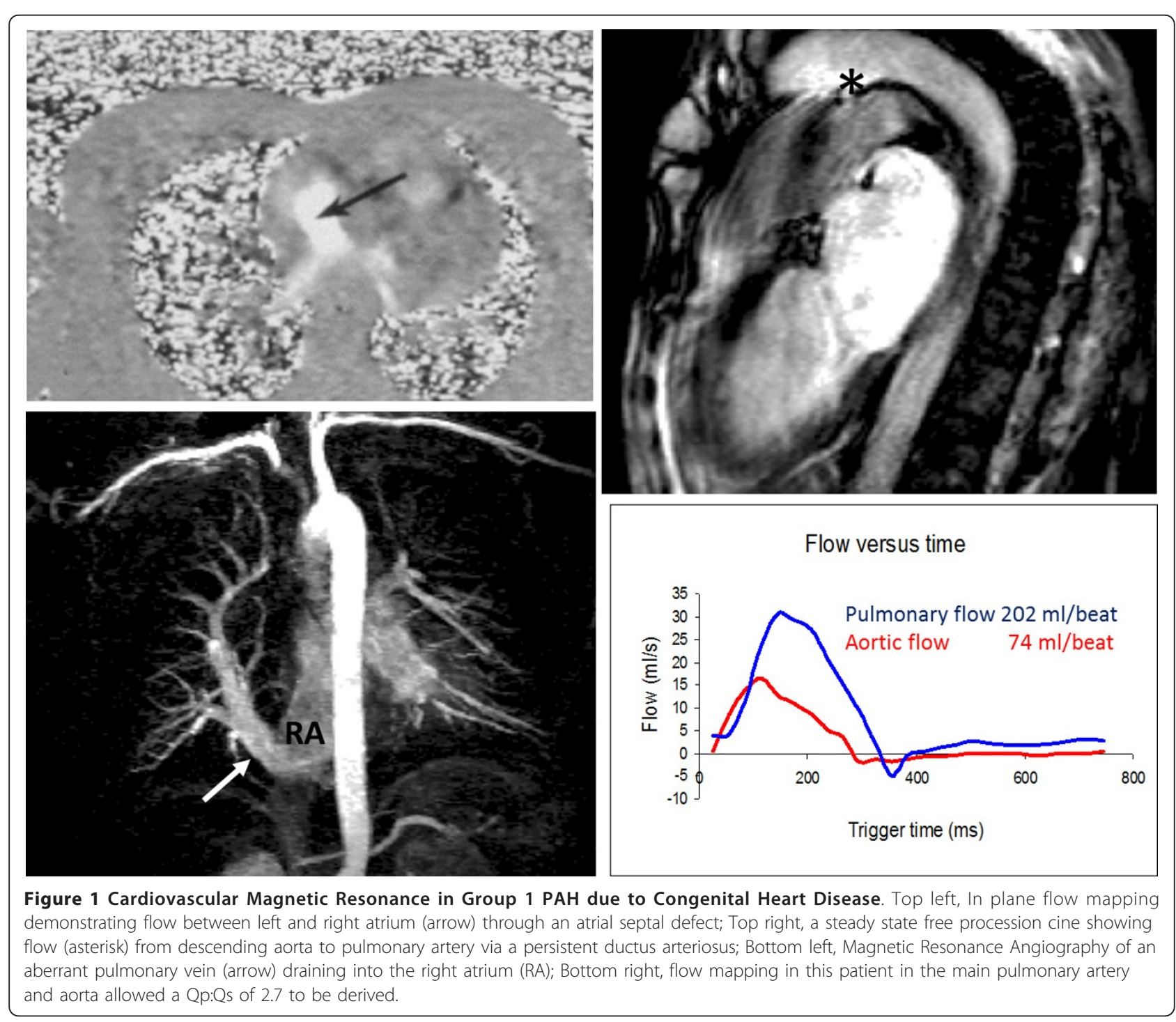


hypertrophy and left atrial dilatation are found in the absence of other causes, especially in patients with diabetes and systemic hypertension. Pulmonary vein stenosis, either idiopathic or occurring after atrial fibrillation ablation therapy [12], can cause PH. The severity of the stenosis can be quantified by flow mapping and visualized with MRA (Figure 2).

Chronic thromboembolic disease can be identified using MRA (Figure 2). However, thrombosis arising insitu can also be found in non-Group 4 patients, particularly in those with Eisenmenger syndrome [13]. More rarely, sarcomas can mimic pulmonary emboli. T1 weighted imaging following injection of gadolinium [14] may be helpful in differentiating the two. A combination of mediastinal lymphadenopathy and a non-coronary pattern of LGE is suggestive of cardiac sarcoid. An absent spleen is an important finding as it is associated with a higher risk of $\mathrm{PH}[15]$.

\section{Acquisition of Volumetric Data}

In routine practice, volumetric data is acquired by aligning the short-axis stack to the LV [16]. In PH, this creates several difficulties. Firstly the RV can dilate beyond the atrioventricular groove, when it appears as a 'shoulder' surrounding the right atrium in the basal short axis. In these cases, end-diastolic RV volume will be underestimated unless the short-axis starts within the atria (Figure 3). Secondly, in severe RV systolic impairment, atrioventricular excursion may not exceed slice thickness. In these instances, the basal slice may contain RV instead of RA at end-systole. To help discriminate RV from RA, atrioventricular excursion should be estimated by cross-referencing short-axis slices against each long axis acquisition $[17,18]$. Tracking an object's motion between slices and frames may also be useful.

It has been suggested that by orientating ventricular acquisition axially [19] or perpendicular to the long axis of the RV [20] these problems will be circumvented. Whilst these approaches improve interobserver reproducibility [19] and reduce differences between right and left ventricular volumes [20], they have not been adopted more widely. In addition, values obtained in this manner cannot be easily compared with normal values established using 'biventricular' analysis [21,22]. These factors argue in favor of the continued use of conventional analysis in patients with $\mathrm{PH}$.

\section{Analysis of Right Ventricular Indices}

There is no consensus as to how RV analysis should be performed. This has become an increasingly relevant issue as enhanced spatial resolution has allowed individual RV papillary muscles and trabeculae to be visualized. Acknowledging that these structures and the interventricular septum hypertrophy in $\mathrm{PH}$, in our centre total RV mass includes the papillary muscles and trabeculae, as well as the 'RV' septum [23] when the interventricular septum is hypertrophied.

Manual analysis offers better control over delineation than semi-automated analysis, reflected in improved interobserver reproducibility [23]. However it is time consuming and requires end-systole to be predefined. This can be difficult in PH due to abnormal interventricular septal motion. One labor-intensive approach is to determine biventricular volumes in the frame exhibiting
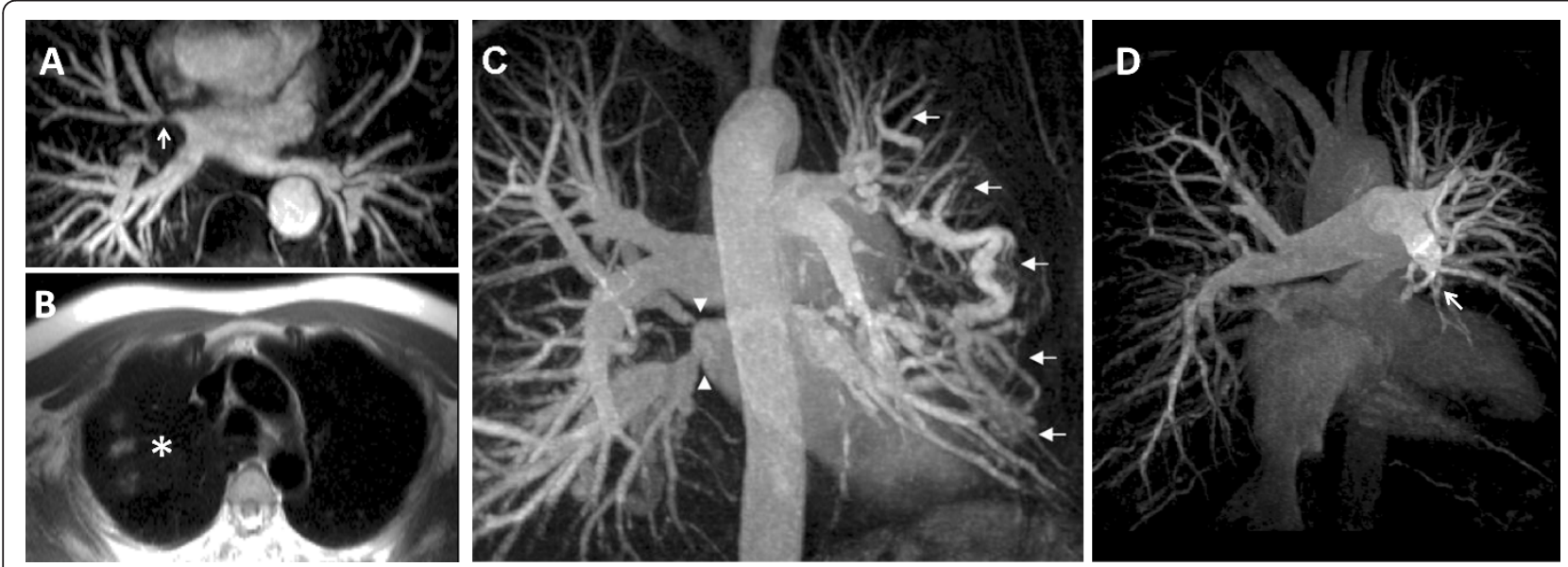

Figure 2 Abnormalities of Pulmonary Vasculature in Pulmonary Hypertension.; (A) White blood anatomy showing right upper pulmonary vein stenosis at the site of a prior ablation for atrial fibrillation (arrow). (B) Congestion and infarction in the right upper lobe on Half-Fourier Acquisition Single-Shot Turbo Spin-Echo images in the same patient (asterisk). (C) Magnetic Resonance Angiography from a separate patient with PH due to fibrosing mediastinitis; a varix is seen bypassing a stenosed left upper pulmonary vein (not shown) alongside stenoses of both right sided pulmonary veins (arrows). (D) Magnetic Resonance Angiography in patient with Chronic Thromboembolic Pulmonary Hypertension. The most striking feature is loss of the left descending pulmonary artery (arrow head). 

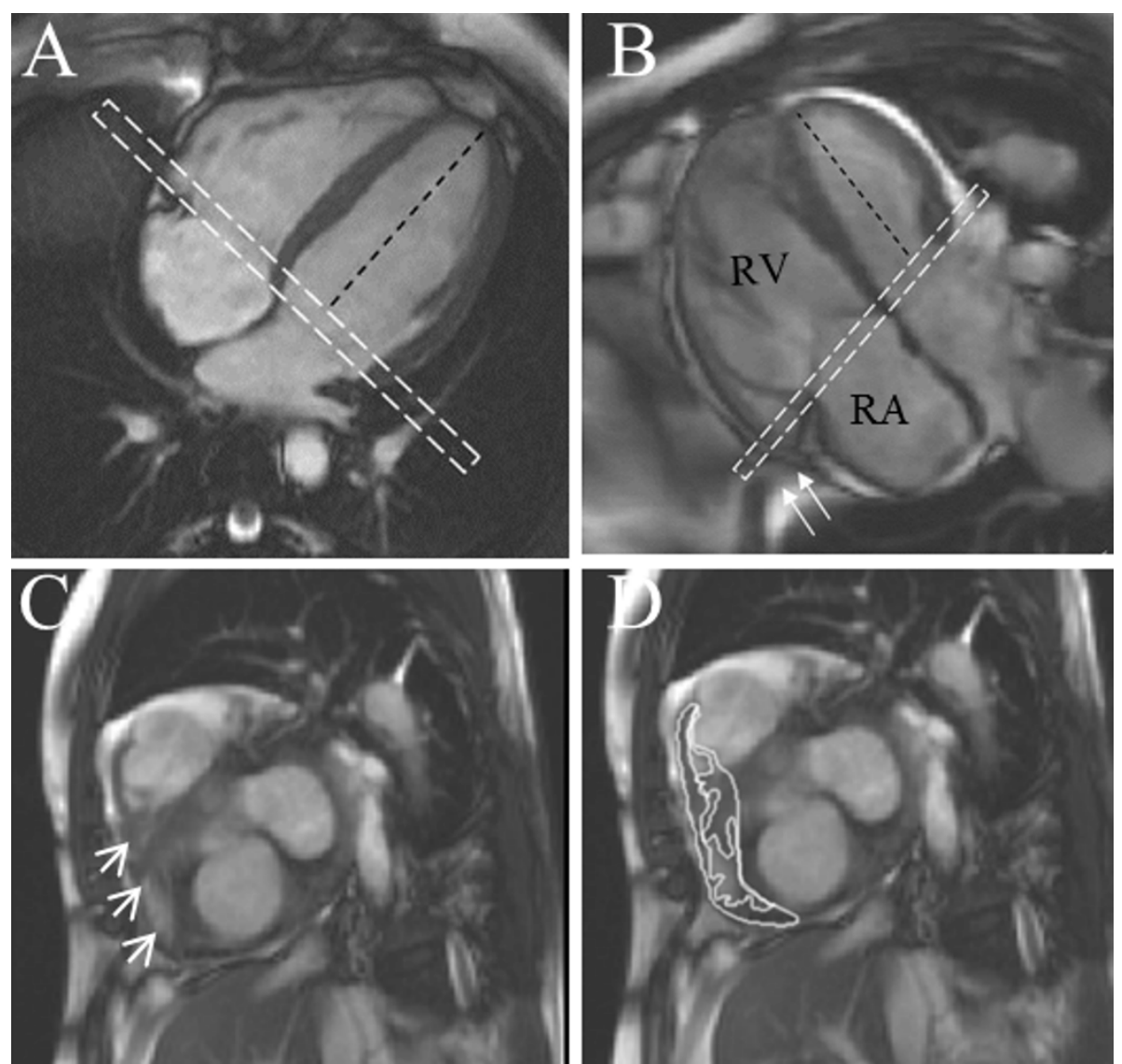

Figure 3 Basal Slice Analysis. In the normal right ventricle (A) the angle between the left ventricular long axis (black dashed line) and basal slice (dashed white box) is approximately $90^{\circ}$. In PH patients (B), assuming the basal slice is prescribed as per recommendations [16] the angle becomes more obtuse as the right ventricle dilates. The basal slice will now include right atrium (seen centrally) with a shoulder of right

ventricle seen laterally $(C$, arrow heads). The impact this interpretation has on delineation is shown in $D$. Also in $B$ note how the most basal part of the right ventricle 'hoods' beyond the TV plane (arrows) and is effectively ignored by the acquisition.

the most abnormal septal position, and the four preceding it, before choosing the smallest volume as end-systole for each ventricle. Alternatively, end-systole can be defined using valve opening and closure.

To simplify RV assessment, surrogate measurements have been developed. One candidate is analysis of transverse motion, which proved to be more strongly correlated with ejection fraction than tricuspid annular plane systolic excursion [24].

\section{Late Gadolinium Enhancement}

The finding of LGE limited to the insertion regions (Figure 4) has been repeatedly demonstrated [25-27] in $\mathrm{PH}$ since first described in 2005 by McCann and colleagues [28]. This has led to speculation that it may reflect pathological fibrosis [25] and hence be a source of ventricular arrhythmias [26]. Proving its histological basis has been difficult. In one of the very few pathology studies of the heart performed in $\mathrm{PH}$, this area was not inspected [29]. In addition, its position is inaccessible to in-vivo biopsy. Pathological correlation in a patient who had died 6 weeks after CMR [30] showed myocardial disarray and plexiform fibrosis at the insertion regions where LGE occurred. These histological features are normally found in the insertion regions since they represent crossing points for left and right ventricular fibres with collagen in between [31]. Hence LGE may reflect pooling of gadolinium within an area of normal myocardium whose architecture has been accentuated by hypertrophy and mechanical stress.

\section{Non-Invasive Assessment of Haemodynamics}

The ability to non-invasively estimate pressures within the right heart is a key objective since it would permit diagnosis and serial assessment without cardiac catheterization. Unfortunately, unlike echocardiography, it is not possible to generate an estimate of RV systolic pressure by measuring the velocity of the tricuspid regurgitant jet. This is because the tricuspid regurgitant jet is dispersed, 

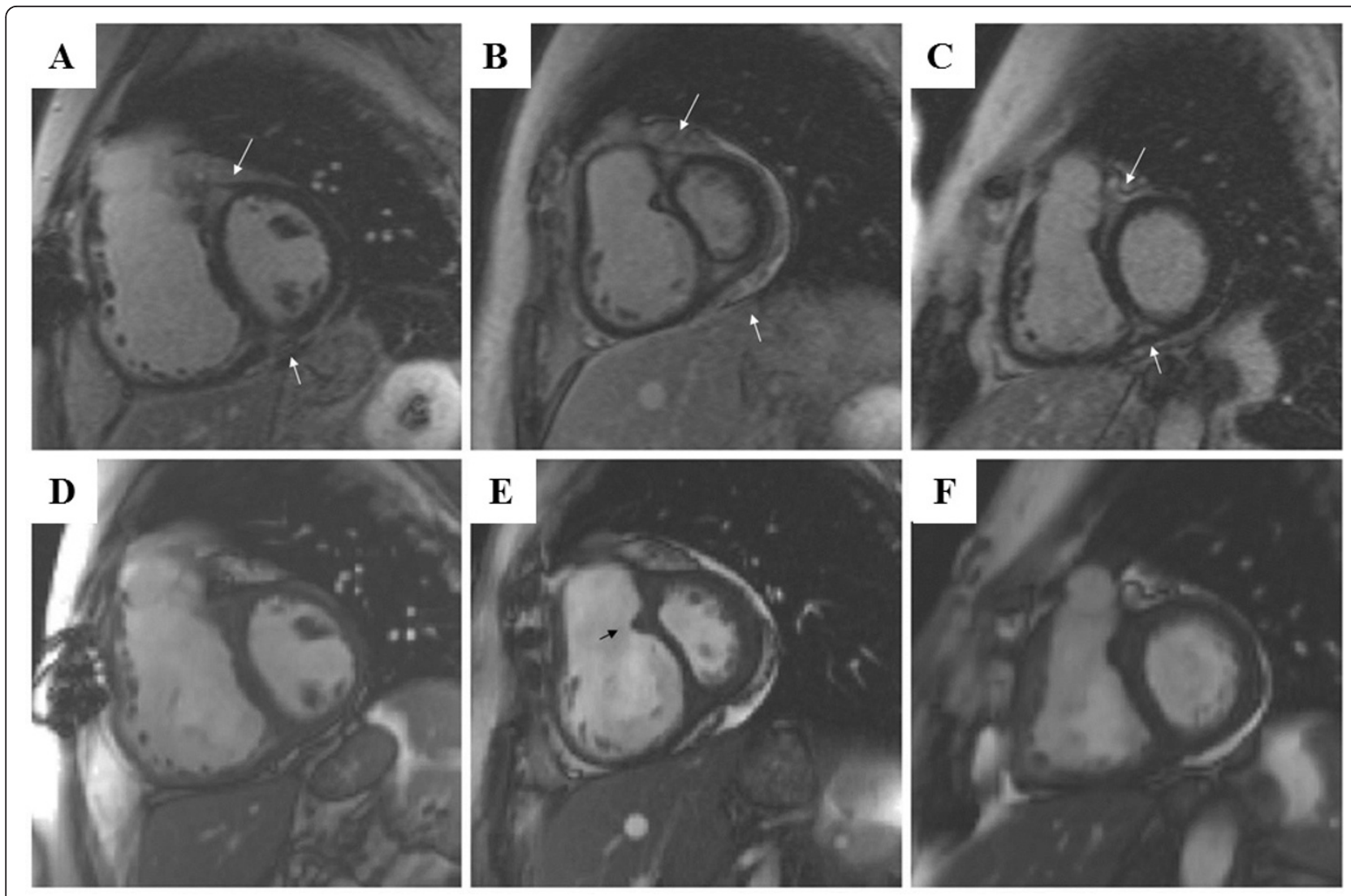

Figure 4 The characteristic late gadolinium enhancement pattern of $\mathrm{PH}$. (A-C) insertion region enhancement (arrows) is triangular in shape with the base at the epicardial surface where both ventricles meet and its apex directed into the interventricular septum. Corresponding short axis cine slices (D-F). The septomarginal trabeculation is arrowed (E) - enhancement is often seen within this structure.

so it is difficult to isolate the highest velocity in either through-plane or in plane acquisitions [32] (Figure 5).

Pulmonary pressures have been estimated by measuring the effects of $\mathrm{PH}$ on the heart. Initial results were encouraging for RV mass [33] but have been mixed subsequently [34]. Based on recent results, the degree of septal displacement may be a more promising measure [35].

CMR derived flow in the main pulmonary artery has also been used to gauge hemodynamics. For example, pulmonary pressures were shown to be inversely correlated with average blood velocity in the main PA [36]. In addition, total pulmonary resistance has been estimated by determining the percentage of regurgitant flow and cross-sectional area of the main pulmonary artery [37], or calculating the ratio of the maximal change in flow rate during ejection to the acceleration volume [38]. Finally, the use of four dimensional flow [39] has built on early work in two dimensional flow [40], to show that in patients with $\mathrm{PH}$, a vortex can be detected in the primary flow direction whose duration correlates well with mPAP.

End-organ effects on the PAs themselves can also be assessed since their distensibility is reduced in PH [41].
It has been shown that a fractional change in the crosssectional area of the main PA of less than $40 \%$ has a high sensitivity for detecting elevated mPAP [42]. Additionally, compliance has been calculated by combining velocity-encoded data and cross-sectional area change of the main PA and deriving pulse pressure through an iterative process [43]. From this, pulse wave velocity (PWV, a measure of vessel stiffness) was derived which had a reliability percentage of $87 \%$ for framing the actual mPAP.

PWV can be calculated directly using the transit time technique by determining flow wave arrival time at two points in the proximal PAs using a high-temporal resolution flow mapping sequence (Figure 6), and dividing the difference by the distance between them [44]. This calculation does not depend on a prior knowledge of PA pressure and raises the possibility of entirely non-invasive assessment of PA stiffness.

The sheer number of indices emphasizes the lack of a single, robust non-invasive measure. Indeed in one independent validation [34], none of the tested parameters accurately predicted mPAP. For CMR to replace cardiac 


\section{Aortic Stenosis Discrete jet with core large enough to measure}

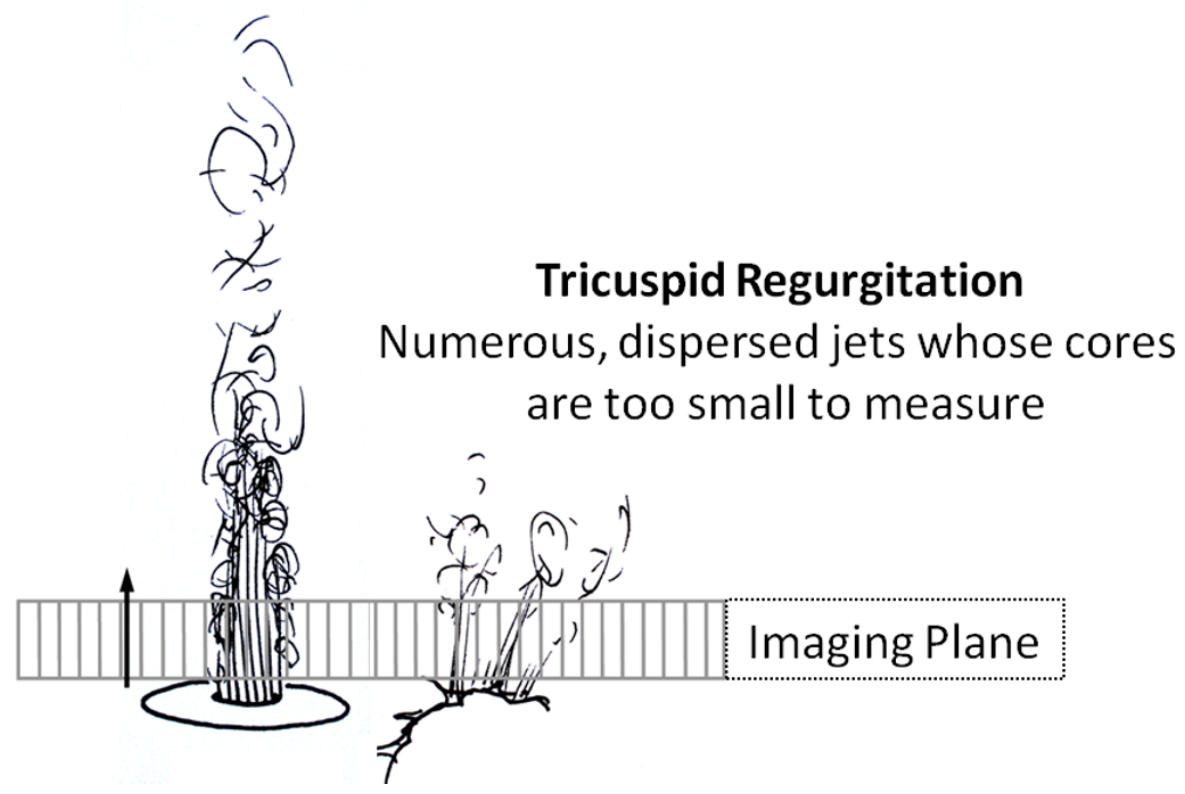

Figure $\mathbf{5}$ Chasing Tricuspid Regurgitation. Accurate jet velocity analysis depends on two factors; positioning of the imaging slice through the jet core and jet core characteristics. The latter is where measurement of tricuspid regurgitation with CMR falls down; compare the discrete stenotic lesion as might be seen in aortic stenosis (left) to the dispersed jets of tricuspid regurgitation (right) and how they relate to the imaging plane (represented by boxed line with direction of velocity measurement arrowed, modified with permission [32]). In functional tricuspid regurgitation, the jets arise at a number of points of failed coaptation and so are numerous and narrow - meaning their core is rarely large enough to be measured.

catheterization, in addition to right heart pressures, left atrial pressure also needs to be estimated. Early work has shown this might be possible through the measurement of transmitral flow and myocardial tissue velocity (i.e. akin to tissue Doppler imaging in echocardiography) [45].

\section{Determining Treatment Effect and Prognosis}

CMR is well suited to longitudinal follow up as it is non-invasive and non-ionizing. Several studies have reported the positive effects medical [46-49] and surgical [50-54] therapies have on RV structure and function. CMR has also been used to determine which patients with idiopathic PAH might benefit from long-term calcium channel blockade by assessing main PA distensibility [55].

This has driven interest in the use of CMR to measure efficacy of new therapies. To date, two proof of concept trials $[48,56]$ have used CMR-derived RV mass as an end-point. This particular surrogate remains unvalidated and may not be the best end-point since it is not known whether a reduction in RV mass is beneficial or harmful to patients.

Using CMR as a trial end-point remains an attractive option since it avoids the limitations associated with the most widely use surrogate in PAH trials; the six minute walk test distance [57]. In addition, fewer patients are required due to its high interstudy repeatability [23].

The RV has been implicated in clinical outcomes from the earliest right heart catheterization studies which showed parameters which could be related to this ventricle (cardiac output, RA pressure and mixed-venous oxygen saturations) were relevant to prognosis $[7,58]$. However it has only been with maturation of single-centre experience (the VU University Medical Center in Amsterdam, The Netherlands) that this assumption has been proven with CMR.

The first outcome study to be reported with CMR [59] demonstrated the importance of indexed biventricular dimensions; a relationship that had not been hitherto revealed by echocardiographic studies. Indexed RV enddiastolic volume was prognostic both at baseline (Figure 7) 


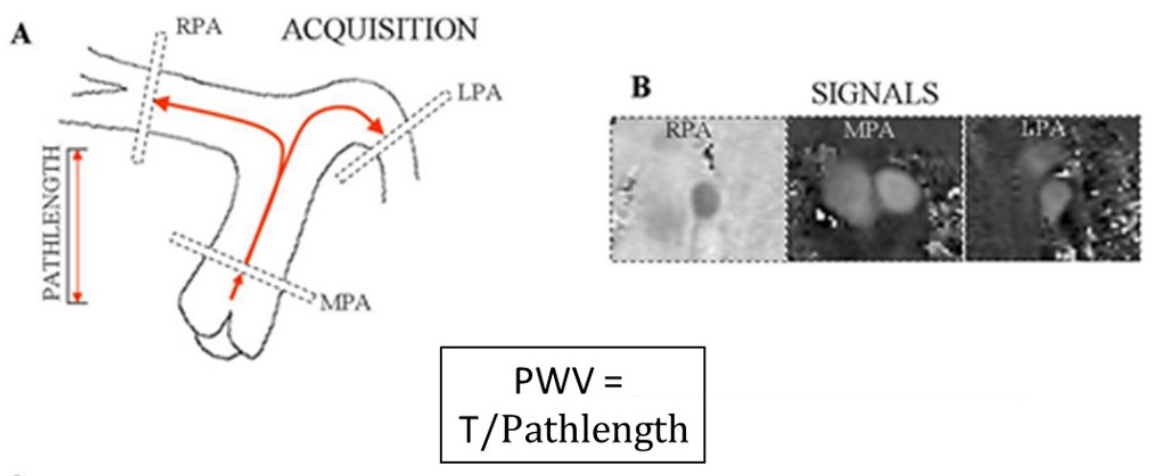

C

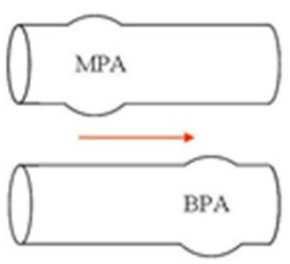

D

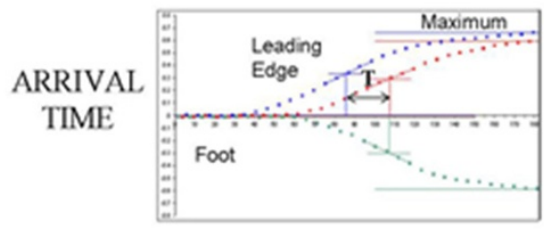

Figure 6 Measuring Transit-Time PWV in the Pulmonary Arteries. Data is acquired in main pulmonary artery, left and right pulmonary artery (A) and the path length between them measured accurately. Using CMR phase-contrast velocity maps (B), the flow pulse is tracked (C) and differences $(T)$ in arrival time ( $D$, in this healthy case defined as halfway between the foot and maximum values) are determined. PWV is then calculated as T/Pathlength. MPA; main pulmonary artery, RPA; right pulmonary artery, LPA; left pulmonary artery, BPA; branch pulmonary artery, PWV; Pulse wave velocity.

and at 1 year as were indexed stroke volume and LV enddiastolic volume. These data have recently been extended to include RV ejection fraction [60]. CMR parameters of PA stiffness are also relevant to prognosis [61] (Figure 7). This emphasizes the point that as the PA become stiffer their ability to buffer pulsatile blood is lost. The RV must compensate for this by generating additional energy to propel blood downstream.

\section{Providing Pathophysiological Insights}

CMR has offered a number of wide-ranging insights into the pathogenesis of $\mathrm{PH}$ through diverse applications (Table 4). By measuring PA distensibility, it has been shown that in patients with normal pulmonary pressures at rest but detectable $\mathrm{PH}$ with exercise, the PAs are stiffer than in normal subjects [42]. The authors speculated that this increased stiffness may itself play a role in accelerating pulmonary vascular remodeling. CMR has demonstrated that left ventricular mass is lower than normal in patients with CTEPH before pulmonary endarterectomy but normalizes afterwards [62]. This is thought to be due to myocardial apoptosis of the chronically underfilled LV. Using tagging, it has been observed that the RV in $\mathrm{PH}$ contracts more slowly than the LV creating interventricular dyssnchrony and subsequent interventricular septal bowing [63].

During CMR perfusion with adenosine stress in patients with $\mathrm{PH}$, biventricular vasoreactivity has been
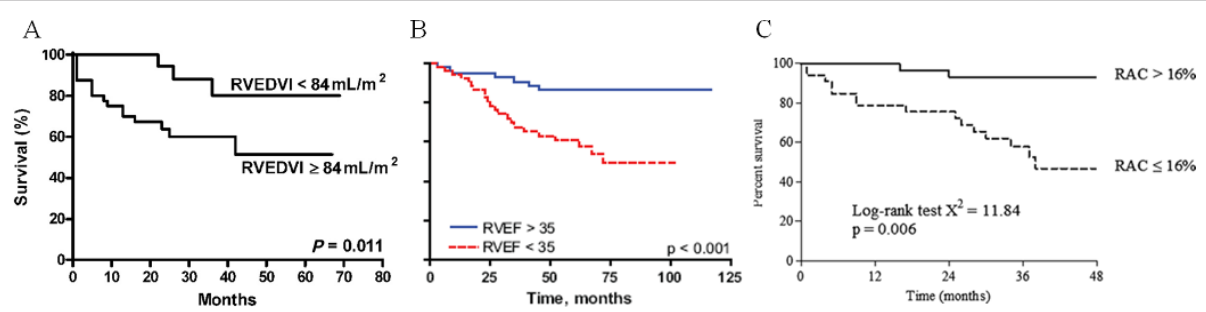

Figure 7 The RV-PA unit and Survival in PAH. Work from the VU University Medical Center (Amsterdam) group demonstrating the importance of right ventricular dilatation [59] (A), ejection fraction[60] (B), and pulmonary artery stiffness [61](C) to prognosis. RVEDVl; indexed right ventricular end-diastolic volume, RVEF; right ventricular ejection fraction, RAC; relative area change. 
Table 4 New Insights Provided by CMR

\begin{tabular}{|c|c|c|}
\hline INSIGHT & CMR METHOD & REF\# \\
\hline \multicolumn{3}{|l|}{ Early Changes } \\
\hline PA stiffens before pulmonary artery pressure increase at rest & Distensibility of pulmonary arteries & [42] \\
\hline \multicolumn{3}{|l|}{ Ventricular Remodeling and Dysfunction } \\
\hline $\begin{array}{l}\text { LV mass is lower in patients with chronic thromboembolic disease but normalizes } \\
\text { post-pulmonary endarterectomy }\end{array}$ & LV mass & [62] \\
\hline $\begin{array}{l}\text { Interventricular dyssnchrony and septal bowing in PAH is due to slower contraction for } \\
\text { the RV than LV }\end{array}$ & Tagging & [63] \\
\hline \multicolumn{3}{|l|}{ Cardiac Ischemia } \\
\hline Both ventricles display attenuated vasoreactivity proportional to mPAP & Adenosine Stress Perfusion & [64] \\
\hline \multicolumn{3}{|l|}{ RV Metabolism } \\
\hline Bosentan improves RV energetics & 31P-NMR spectroscopy & [65] \\
\hline \multicolumn{3}{|l|}{ Ventricular-arterial Decoupling in PH } \\
\hline $\begin{array}{l}\text { Disconnect occurs since increases in arterial load are far greater than those in } \\
\text { contractility }\end{array}$ & $\begin{array}{l}\text { Volumes combined with invasively derived } \\
\text { pressure loops/pressures }\end{array}$ & {$[66,67]$} \\
\hline \multicolumn{3}{|l|}{ Changes with Exercise } \\
\hline $\begin{array}{l}\text { Stroke volume in PAH fails to augment - increases in cardiac output are mediated by } \\
\text { heart rate alone }\end{array}$ & Bicycle exercise & [68] \\
\hline \multicolumn{3}{|l|}{ Inaccuracy of Catheter-Laboratory Measurements } \\
\hline $\begin{array}{l}\text { Pulmonary vascular resistance derived from the Fick method is inaccurate in conditions } \\
\text { of vasodilatation }\end{array}$ & Flow combined with invasively derived pressure & [69] \\
\hline
\end{tabular}

found to be diminished. The degree to which this occurs in both ventricles could be predicted from mPAP [64]. Despite its potential, nuclear magnetic resonance (NMR) spectroscopy remains relatively unexplored in $\mathrm{PH}$. An isolated case report using 31P-NMR spectroscopy offers a unique insight into the failing RV by showing how RV energetics are disturbed in PAH but improve with bosentan treatment [65].

Interventional CMR allows RV pressure-volume loops to be created from which three key measures are extracted: 1) Systolic function (Emax; end-systolic pressure divided by end-systolic volume, 2) Afterload (Ea; end-systolic pressure divided by stroke volume) and 3) Ventricular-arterial coupling (Emax/Ea). In patients with PAH, Kuehne and colleagues [66] found that while systolic function was increased, the increase in arterial elastance was relatively greater leading to ventriculararterial decoupling. These findings have been echoed more recently in a larger cohort of patients with $\mathrm{PH}$ (albeit using different definitions of Emax and Ea) [67].

Exercise CMR, performed on a recumbent bicycle within the scanner, has been used to demonstrate that exercise-induced increases in cardiac output in patients with idiopathic $\mathrm{PAH}$ are due to heart rate changes alone, since stroke volume fails to augment [68]. CMR has also detailed inaccuracies with the Fick method for determining cardiac output in conditions of high pulmonary blood flow or increased oxygen concentration [69].

\section{Future Directions}

CMR is unlikely to be more widely integrated into a general imaging pathway in $\mathrm{PH}$ until its incremental value is proven in routine clinical practice. To determine whether this is the case, clinical trials of CMR imaging should be undertaken comparing standard care in $\mathrm{PH}$ with that informed by CMR results. It is also important that analysis become standardized and facilitated by improved software.

It has also been suggested that CMR be used to 'screen' potential therapies before they are selected for definitive, long-term studies [70]. Before doing so, CMR parameters need to be validated [71]. One aspect of this involves determining which of the available measures best reflects prognosis. This should include an exploration of load-independent end-points, such as ventricular tagging.

Like most research in $\mathrm{PH}, \mathrm{CMR}$-based work has been mainly applied to Group 1 (PAH). It remains unclear whether the RV in each group behaves differently in the face of similar pulmonary pressures. Through contemporaneous assessment of the RV-PA functional unit, CMR might be able to contribute to an answer, and if this assertion is correct, explain why.

Work should continue to define the relevance of flow wave morphology and pulmonary artery stiffness with focus extended to non-invasively determining left atrial pressure. The opportunity to validate this work is 
offered by the interventional CMR suite. Finally, small animal CMR is being explored although it should be acknowledged that animal models of PAH are unreliable in predicting human responses.

\section{Conclusions}

CMR permits an accurate assessment of the right ventricle and pulmonary artery flow. In current clinical practice, it is an especially useful tool in patients with a diagnosis of (or suspected of having) PAH associated with congenital heart disease. However it also allows discrimination of other features which might point to an alternative etiology. It is a flexible research tool which has opened new avenues for understanding treatment effects, outcomes and pathogenesis. It appears inevitable that its place in the management of $\mathrm{PH}$ will evolve as evidence supporting its use accumulates.

\section{List of Abbreviations}

CMR: Cardiovascular Magnetic Resonance; CTEPH: chronic thromboembolic pulmonary hypertension; EF: ejection fraction; HASTE: Half-Fourier Acquisition Single-Shot Turbo Spin-Echo; LGE: Late Gadolinium Enhancement; LV: left ventricle; PAH: pulmonary arterial hypertension; mPAP: mean pulmonary arterial pressure; MRA: magnetic resonance angiography; PA: pulmonary artery; PH: pulmonary hypertension; PVR: pulmonary vascular resistance; PWV: Pulse wave velocity; RA: right atrium; RV: right ventricle; SSFP: steady state free procession.

\section{Acknowledgements}

Dr Bradlow was supported by a British Heart Foundation Junior Fellowship Grant. This work was also supported by the NIHR Cardiovascular Biomedical Research Unit of Royal Brompton and Harefield NHS Foundation Trust and Imperial College London.

\section{Author details}

${ }^{1}$ Cardiovascular Magnetic Resonance Unit, Royal Brompton Hospital, London, UK. ${ }^{2}$ Pulmonary Hypertension Service, Hammersmith Hospital, London, UK.

\section{Authors' contributions}

All authors participated in literature review, manuscript preparation and final approval of the submitted manuscript.

\section{Competing interests}

The authors declare that they have no competing interests.

Received: 10 July 2011 Accepted: 18 January 2012

Published: 18 January 2012

\section{References}

1. Galie N, Hoeper MM, Humbert M, Torbicki A, Vachiery JL, Barbera JA, Beghetti M, Corris P, Gaine S, Gibbs JS, et al: Guidelines for the diagnosis and treatment of pulmonary hypertension: the Task Force for the Diagnosis and Treatment of Pulmonary Hypertension of the European Society of Cardiology (ESC) and the European Respiratory Society (ERS), endorsed by the International Society of Heart and Lung Transplantation (ISHLT). Eur Heart J 2009, 30:2493-2537.

2. Humbert M, Sitbon O, Chaouat A, Bertocchi M, Habib G, Gressin V, Yaici A, Weitzenblum E, Cordier JF, Chabot F, et al: Survival in patients with idiopathic, familial, and anorexigen-associated pulmonary arterial hypertension in the modern management era. Circulation 122:156-163.

3. Lang IM, Plank C, Sadushi-Kolici R, Jakowitsch J, Klepetko W, Maurer G: Imaging in pulmonary hypertension. JACC CardiovasC Imaging 3:1287-1295.
4. von Schulthess GK, Fisher MR, Higgins CB: Pathologic blood flow in pulmonary vascular disease as shown by gated magnetic resonance imaging. Ann Intern Med 1985, 103:317-323.

5. Mackey ES, Sandler MP, Campbell RM, Graham TP Jr, Atkinson JB, Price R, Moreau GA: Right ventricular myocardial mass quantification with magnetic resonance imaging. Am J Cardiol 1990, 65:529-532.

6. Boxt LM, Katz J: Magnetic resonance imaging for quantitation of right ventricular volume in patients with pulmonary hypertension. J Thorac Imaging 1993, 8:92-97.

7. D'Alonzo GE, Barst RJ, Ayres SM, Bergofsky EH, Brundage BH, Detre KM, Fishman AP, Goldring RM, Groves BM, Kernis JT, et al: Survival in patients with primary pulmonary hypertension. Results from a national prospective registry. Ann Intern Med 1991, 115:343-349.

8. Raymond RJ, Hinderliter AL, Willis PW, Ralph D, Caldwell EJ, Williams W, Ettinger NA, Hill NS, Summer WR, de Boisblanc B, et al: Echocardiographic predictors of adverse outcomes in primary pulmonary hypertension. J Am Coll Cardiol 2002, 39:1214-1219.

9. Heath D, Edwards JE: Configuration of elastic tissue of pulmonary trunk in idiopathic pulmonary hypertension. Circulation 1960, 21:59-62.

10. Mauritz GJ, Marcus JT, Boonstra A, Postmus PE, Westerhof N, VonkNoordegraaf A: Non-invasive stroke volume assessment in patients with pulmonary arterial hypertension: left-sided data mandatory. J Cardiovasc Magn Reson 2008, 10:51.

11. Kafka H, Mohiaddin RH: Cardiac MRI and pulmonary MR angiography of sinus venosus defect and partial anomalous pulmonary venous connection in cause of right undiagnosed ventricular enlargement. AJR Am J Roentgenol 2009, 192:259-266.

12. Robbins IM, Colvin EV, Doyle TP, Kemp WE, Loyd JE, McMahon WS, Kay GN: Pulmonary vein stenosis after catheter ablation of atrial fibrillation. Circulation 1998, 98:1769-1775.

13. Broberg CS, Ujita M, Prasad S, Li W, Rubens M, Bax BE, Davidson SJ, Bouzas B, Gibbs JS, Burman J, Gatzoulis MA: Pulmonary arterial thrombosis in eisenmenger syndrome is associated with biventricular dysfunction and decreased pulmonary flow velocity. J Am Coll Cardiol 2007, 50:634-642.

14. Kauczor HU, Schwickert HC, Mayer E, Kersjes W, Moll R, Schweden F: Pulmonary artery sarcoma mimicking chronic thromboembolic disease: computed tomography and magnetic resonance imaging findings. Cardiovasc Intervent Radiol 1994, 17:185-189.

15. Hoeper MM, Niedermeyer J, Hoffmeyer F, Flemming P, Fabel H: Pulmonary hypertension after splenectomy? Ann Intern Med 1999, 130:506-509.

16. Kramer CM, Barkhausen J, Flamm SD, Kim RJ, Nagel E: Standardized cardiovascular magnetic resonance imaging (CMR) protocols, society for cardiovascular magnetic resonance: board of trustees task force on standardized protocols. J Cardiovasc Magn Reson 2008, 10:35.

17. Mooij CF, de Wit CJ, Graham DA, Powell AJ, Geva T: Reproducibility of MRI measurements of right ventricular size and function in patients with normal and dilated ventricles. J Magn Reson Imaging 2008, 28:67-73.

18. Geva T: Repaired tetralogy of Fallot: the roles of cardiovascular magnetic resonance in evaluating pathophysiology and for pulmonary valve replacement decision support. J Cardiovasc Magn Reson 2011, 13:9.

19. Alfakih K, Plein S, Bloomer T, Jones T, Ridgway J, Sivananthan M: Comparison of right ventricular volume measurements between axial and short axis orientation using steady-state free precession magnetic resonance imaging. J Magn Reson Imaging 2003, 18:25-32.

20. Strugnell WE, Slaughter RE, Riley RA, Trotter AJ, Bartlett H: Modified RV short axis series-a new method for cardiac MRI measurement of right ventricular volumes. J Cardiovasc Magn Reson 2005, 7:769-774.

21. Maceira AM, Prasad SK, Khan M, Pennell DJ: Reference right ventricular systolic and diastolic function normalized to age, gender and body surface area from steady-state free precession cardiovascular magnetic resonance. Eur Heart J 2006, 27:2879-2888.

22. Kawut SM, Lima JA, Barr RG, Chahal H, Jain A, Tandri H, Praestgaard A, Bagiella E, Kizer JR, Johnson WC, et al: Sex and race differences in right ventricular structure and function: the multi-ethnic study of atherosclerosis-right ventricle study. Circulation 123:2542-2551.

23. Bradlow WM, Hughes ML, Keenan NG, Bucciarelli-Ducci C, Assomull R, Gibbs JS, Mohiaddin RH: Measuring the heart in pulmonary arterial hypertension (PAH): implications for trial study size. J Magn Reson Imaging 2010, 31:117-124. 
24. Kind T, Mauritz GJ, Marcus JT, van de Veerdonk M, Westerhof N, VonkNoordegraaf A: Right ventricular ejection fraction is better reflected by transverse rather than longitudinal wall motion in pulmonary hypertension. J Cardiovasc Magn Reson 2010, 12:35.

25. Blyth KG, Groenning BA, Martin TN, Foster JE, Mark PB, Dargie HJ, Peacock AJ: Contrast enhanced-cardiovascular magnetic resonance imaging in patients with pulmonary hypertension. Eur Heart J 2005, 26:1993-1999.

26. McCann GP, Gan CT, Beek AM, Niessen HW, Vonk Noordegraaf A, van Rossum AC: Extent of MRI delayed enhancement of myocardial mass is related to right ventricular dysfunction in pulmonary artery hypertension. AJR Am J Roentgenol 2007, 188:349-355.

27. Sanz J, Dellegrottaglie S, Kariisa M, Sulica R, Poon M, O'Donnell TP, Mehta D, Fuster V, Rajagopalan S: Prevalence and correlates of septal delayed contrast enhancement in patients with pulmonary hypertension. Am J Cardiol 2007, 100:731-735.

28. McCann GP, Beek AM, Vonk-Noordegraaf A, van Rossum AC: Delayed contrast-enhanced magnetic resonance imaging in pulmonary arterial hypertension. Circulation 2005, 112:e268.

29. Bradley SP, Auger WR, Moser KM, Fedullo PF, Channick RN, Bloor CM: Right ventricular pathology in chronic pulmonary hypertension. Am J Cardiol 1996, 78:584-587.

30. Bradlow WM, Assomull R, Kilner PJ, Gibbs JS, Sheppard MN, Mohiaddin RH: Understanding late gadolinium enhancement in pulmonary hypertension. Circ Cardiovasc Imaging 2010, 3:501-503.

31. Kuribayashi T, Roberts WC: Myocardial disarray at junction of ventricular septum and left and right ventricular free walls in hypertrophic cardiomyopathy. Am J Cardiol 1992, 70:1333-1340.

32. Kilner PJ, Gatehouse PD, Firmin DN: Flow measurement by magnetic resonance: a unique asset worth optimising. J Cardiovasc Magn Reson 2007, 9:723-728.

33. Saba TS, Foster J, Cockburn M, Cowan M, Peacock AJ: Ventricular mass index using magnetic resonance imaging accurately estimates pulmonary artery pressure. Eur Respir J 2002, 20:1519-1524.

34. Roeleveld RJ, Marcus JT, Boonstra A, Postmus PE, Marques KM, Bronzwaer JG, Vonk-Noordegraaf A: A comparison of noninvasive MRIbased methods of estimating pulmonary artery pressure in pulmonary hypertension. J Magn Reson Imaging 2005, 22:67-72.

35. Roeleveld RJ, Marcus JT, Faes TJ, Gan TJ, Boonstra A, Postmus PE, VonkNoordegraaf A: Interventricular septal configuration at mr imaging and pulmonary arterial pressure in pulmonary hypertension. Radiology 2005, 234:710-717.

36. Sanz J, Kuschnir P, Rius T, Salguero R, Sulica R, Einstein AJ, Dellegrottaglie S, Fuster V, Rajagopalan S, Poon M: Pulmonary arterial hypertension: noninvasive detection with phase-contrast MR imaging. Radiology 2007, 243:70-79.

37. Kondo C, Caputo GR, Masui T, Foster E, O'Sullivan M, Stulbarg MS, Golden J, Catterjee K, Higgins CB: Pulmonary hypertension: pulmonary flow quantification and flow profile analysis with velocity-encoded cine MR imaging. Radiology 1992, 183:751-758.

38. Mousseaux E, Tasu JP, Jolivet O, Simonneau G, Bittoun J, Gaux JC: Pulmonary arterial resistance: noninvasive measurement with indexes of pulmonary flow estimated at velocity-encoded MR imaging-preliminary experience. Radiology 1999, 212:896-902.

39. Reiter G, Reiter U, Kovacs G, Kainz B, Schmidt K, Maier R, Olschewski H, Rienmueller R: Magnetic resonance-derived 3-dimensional blood flow patterns in the main pulmonary artery as a marker of pulmonary hypertension and a measure of elevated mean pulmonary arterial pressure. Circ Cardiovasc Imaging 2008, 1:23-30.

40. Mohiaddin $\mathrm{RH}$, Yang GZ, Kilner PJ: Visualization of flow by vector analysis of multidirectional cine MR velocity mapping. J Comput Assist Tomogr 1994, 18:383-392.

41. Bogren $H G$, Klipstein RH, Mohiaddin RH, Firmin DN, Underwood SR, Rees RS, Longmore DB: Pulmonary artery distensibility and blood flow patterns: a magnetic resonance study of normal subjects and of patients with pulmonary arterial hypertension. Am Heart J 1989, 118:990-999.

42. Sanz J, Kariisa M, Dellegrottaglie S, Prat-Gonzalez S, Garcia MJ, Fuster V, Rajagopalan S: Evaluation of pulmonary artery stiffness in pulmonary hypertension with cardiac magnetic resonance. JACC Cardiovasc Imaging 2009, 2:286-295.
43. Laffon E, Laurent F, Bernard V, De Boucaud L, Ducassou D, Marthan R: Noninvasive assessment of pulmonary arterial hypertension by MR phase-mapping method. J App/ Physiol 2001, 90:2197-2202.

44. Bradlow WM, Gatehouse PD, Hughes RL, O'Brien AB, Gibbs JS, Firmin DN, Mohiaddin $\mathrm{RH}$ : Assessing normal pulse wave velocity in the proximal pulmonary arteries using transit time: a feasibility, repeatability, and observer reproducibility study by cardiovascular magnetic resonance. $J$ Magn Reson Imaging 2007, 25:974-981.

45. Paelinck BP, de Roos A, Bax JJ, Bosmans JM, van Der Geest RJ, Dhondt D, Parizel PM, Vrints CJ, Lamb HJ: Feasibility of tissue magnetic resonance imaging: a pilot study in comparison with tissue Doppler imaging and invasive measurement. J Am Coll Cardiol 2005, 45:1109-1116.

46. Roeleveld RJ, Vonk-Noordegraaf A, Marcus JT, Bronzwaer JG, Marques KM, Postmus PE, Boonstra A: Effects of epoprostenol on right ventricular hypertrophy and dilatation in pulmonary hypertension. Chest 2004, 125:572-579.

47. Michelakis ED, Tymchak W, Noga M, Webster L, Wu XC, Lien D, Wang SH, Modry D, Archer SL: Long-term treatment with oral sildenafil is safe and improves functional capacity and hemodynamics in patients with pulmonary arterial hypertension. Circulation 2003, 108:2066-2069.

48. Wilkins MR, Paul GA, Strange JW, Tunariu N, Gin-Sing W, Banya WA, Westwood MA, Stefanidis A, Ng LL, Pennell DJ, et al: Sildenafil versus Endothelin Receptor Antagonist for Pulmonary Hypertension (SERAPH) study. Am J Respir Crit Care Med 2005, 171:1292-1297.

49. van Wolferen SA, Boonstra A, Marcus JT, Marques KM, Bronzwaer JG, Postmus PE, Vonk-Noordegraaf A: Right ventricular reverse remodelling after sildenafil in pulmonary arterial hypertension. Heart 2006, 92:1860-1861.

50. Frist WH, Lorenz CH, Walker ES, Loyd JE, Stewart JR, Graham TP Jr, Pearlstein DP, Key SP, Merrill WH: MRI complements standard assessment of right ventricular function after lung transplantation. Ann Thorac Surg 1995, 60:268-271.

51. Moulton MJ, Creswell LL, Ungacta FF, Downing SW, Szabo BA, Pasque MK: Magnetic resonance imaging provides evidence for remodeling of the right ventricle after single-lung transplantation for pulmonary hypertension. Circulation 1996, 94:11312-319.

52. Kasimir MT, Seebacher G, Jaksch P, Winkler G, Schmid K, Marta GM, Simon P, Klepetko W: Reverse cardiac remodelling in patients with primary pulmonary hypertension after isolated lung transplantation. Eur J Cardiothorac Surg 2004, 26:776-781.

53. D’Armini AM, Zanotti G, Ghio S, Magrini G, Pozzi M, Scelsi L, Meloni G, Klersy $C$, Vigano M: Reverse right ventricular remodeling after pulmonary endarterectomy. J Thorac Cardiovasc Surg 2007, 133:162-168.

54. Reesink HJ, Marcus JT, Tulevski II, Jamieson S, Kloek JJ, Vonk Noordegraaf A, Bresser P: Reverse right ventricular remodeling after pulmonary endarterectomy in patients with chronic thromboembolic pulmonary hypertension: utility of magnetic resonance imaging to demonstrate restoration of the right ventricle. J Thorac Cardiovasc Surg 2007, 133:58-64.

55. Jardim C, Rochitte CE, Humbert M, Rubenfeld G, Jasinowodolinski D, Carvalho CR, Souza R: Pulmonary artery distensibility in pulmonary arterial hypertension: an MRI pilot study. Eur Respir J 2007, 29:476-481.

56. Wilkins MR, Ali O, Bradlow W, Wharton J, Taegtmeyer A, Rhodes CJ, Ghofrani HA, Howard L, Nihoyannopoulos P, Mohiaddin RH, et al: Simvastatin as a Treatment for Pulmonary Hypertension Trial (SiPHT). Am J Respir Crit Care Med 2010.

57. Macchia A, Marchioli R, Marfisi R, Scarano M, Levantesi G, Tavazzi L, Tognoni G: A meta-analysis of trials of pulmonary hypertension: a clinical condition looking for drugs and research methodology. Am Heart J 2007, 153:1037-1047.

58. Fuster V, Steele PM, Edwards WD, Gersh BJ, McGoon MD, Frye RL: Primary pulmonary hypertension: natural history and the importance of thrombosis. Circulation 1984, 70:580-587.

59. van Wolferen SA, Marcus JT, Boonstra A, Marques KM, Bronzwaer JG, Spreeuwenberg MD, Postmus PE, Vonk-Noordegraaf A: Prognostic value of right ventricular mass, volume, and function in idiopathic pulmonary arterial hypertension. Eur Heart J 2007, 28:1250-1257.

60. van de Veerdonk MC, Kind T, Marcus JT, Mauritz GJ, Heymans MW, Bogaard HJ, Boonstra A, Marques KM, Westerhof N, Vonk-Noordegraaf A Progressive right ventricular dysfunction in patients with pulmonary arterial hypertension responding to therapy. J Am Coll Cardiol 58:2511-2519. 
61. Gan CT, Lankhaar JW, Westerhof N, Marcus JT, Becker A, Twisk JW Boonstra A, Postmus PE, Vonk-Noordegraaf A: Noninvasively assessed pulmonary artery stiffness predicts mortality in pulmonary arterial hypertension. Chest 2007, 132:1906-1912.

62. Hardziyenka M, Campian ME, Reesink HJ, Surie S, Bouma BJ, Groenink M, Klemens CA, Beekman L, Remme CA, Bresser P, Tan HL: Right ventricular failure following chronic pressure overload is associated with reduction in left ventricular mass evidence for atrophic remodeling. J Am Coll Cardiol 57:921-928.

63. Marcus JT, Gan CT, Zwanenburg JJ, Boonstra A, Allaart CP, Gotte MJ, VonkNoordegraaf A: Interventricular mechanical asynchrony in pulmonary arterial hypertension: left-to-right delay in peak shortening is related to right ventricular overload and left ventricular underfilling. J Am Coll Cardiol 2008, 51:750-757.

64. Vogel-Claussen J, Skrok J, Shehata ML, Singh S, Sibley CT, Boyce DM, Lechtzin N, Girgis RE, Mathai SC, Goldstein TA, et al: Right and left ventricular myocardial perfusion reserves correlate with right ventricular function and pulmonary hemodynamics in patients with pulmonary arterial hypertension. Radiology 258:119-127.

65. Spindler M, Schmidt M, Geier O, Sandstede J, Hahn D, Ertl G, Beer M: Functional and metabolic recovery of the right ventricle during Bosentan therapy in idiopathic pulmonary arterial hypertension. $J$ Cardiovasc Magn Reson 2005, 7:853-854.

66. Kuehne T, Yilmaz S, Steendijk P, Moore P, Groenink M, Saaed M, Weber O, Higgins $C B$, Ewert $P$, Fleck $E$, et al: Magnetic resonance imaging analysis of right ventricular pressure-volume loops: in vivo validation and clinical application in patients with pulmonary hypertension. Circulation 2004 110:2010-2016.

67. Sanz J, Garcia-Alvarez A, Fernandez-Friera L, Nair A, Mirelis JG, Sawit ST, Pinney S, Fuster V: Right ventriculo-arterial coupling in pulmonary hypertension: a magnetic resonance study. Heart 2012, 98:238-243.

68. Holverda S, Gan CT, Marcus JT, Postmus PE, Boonstra A, VonkNoordegraaf A: Impaired stroke volume response to exercise in pulmonary arterial hypertension. J Am Coll Cardiol 2006, 47:1732-1733.

69. Muthurangu V, Taylor A, Andriantsimiavona R, Hegde S, Miquel ME, Tulloh R, Baker E, Hill DL, Razavi RS: Novel method of quantifying pulmonary vascular resistance by use of simultaneous invasive pressure monitoring and phase-contrast magnetic resonance flow. Circulation 2004, 110:826-834

70. Ghofrani HA, Wilkins MW, Rich S: Uncertainties in the diagnosis and treatment of pulmonary arterial hypertension. Circulation 2008, 118:1195-1201.

71. Fleming TR, DeMets DL: Surrogate end points in clinical trials: are we being misled? Ann Intern Med 1996, 125:605-613.

72. Bossone E, Bodini BD, Mazza A, Allegra L: Pulmonary arterial hypertension: the key role of echocardiography. Chest 2005, 127:1836-1843.

73. Goodman DJ, Harrison DC, Popp RL: Echocardiographic features of primary pulmonary hypertension. Am J Cardiol 1974, 33:438-443.

74. Marcus JT, Vonk Noordegraaf A, Roeleveld RJ, Postmus PE, Heethaar RM, Van Rossum AC, Boonstra A: Impaired left ventricular filling due to right ventricular pressure overload in primary pulmonary hypertension: noninvasive monitoring using MRI. Chest 2001, 119:1761-1765.

75. Maron BJ, Clark CE, Henry WL, Fukuda T, Edwards JE, Mathews EC Jr, Redwood DR, Epstein SE: Prevalence and characteristics of disproportionate ventricular septal thickening in patients with acquired or congenital heart diseases: echocardiographic and morphologic findings. Circulation 1977, 55:489-496.

doi:10.1186/1532-429X-14-6

Cite this article as: Bradlow et al:: Cardiovascular magnetic resonance in pulmonary hypertension. Journal of Cardiovascular Magnetic Resonance 2012 14:6.

\section{Submit your next manuscript to BioMed Central and take full advantage of:}

- Convenient online submission

- Thorough peer review

- No space constraints or color figure charges

- Immediate publication on acceptance

- Inclusion in PubMed, CAS, Scopus and Google Scholar

- Research which is freely available for redistribution

Submit your manuscript at www.biomedcentral.com/submit
Biomed Central 